\title{
RECENSIÓN
}

\section{SALUD LABORAL. CONCEPTOS Y TÉCNICAS PARA LA PREVENCIÓN DE RIESGOS LABORALES}

\author{
Benavides FG, Ruiz. Frutos C, García García AM. \\ Masson. Barcelona \\ Año 1997. \\ ISBN \\ 385 páginas. \\ Recensión: Monserrat García Gómez. Subdirección General de Epidemiología, Promoción y Educación para la Sa- \\ lud. Dirección General de Salud Pública. Ministerio de Sanidad y Consumo
}

El libro sobre Salud Laboral que Fernando García Benavides, Carlos Ruiz Frutos y Ana M. ${ }^{a}$ García García han dirigido y coordinado, nos proporciona una introducción básica pero a la vez completa, a la amplitud de contenidos y técnicas necesarios para la prevención de riesgos laborales.

Tras la aprobación de la Ley 31/1995, de Prevención de Riesgos Laborales, y el Reglamento de los Servicios de Prevención, se hacen necesarias nuevas capacidades o aptitudes para el desarrollo de la actividad preventiva en las empresas que, obligadamente, deben ser adquiridas por los futuros profesionales a través de una buena formación. Estos profesionales, procedentes de diferentes disciplinas, deben formarse en prevención de riesgos laborales, tanto en los contenidos de la propia disciplina como en los de las demás, con el objetivo de adquirir el lenguaje común necesario al equipo multidisciplinar, para resolver los problemas que surgen en los centros de trabajo.

Mediante una correcta selección de materias y una redacción amena y práctica, la presente obra tiene el mérito de hacer digerible la amplitud de materias que se deben tener en cuenta para prevenir los riesgos de origen laboral.

El libro se estructura en cinco partes, y está prologado por la profesora Claire Infante-Rivard. Redactado en un lenguaje claro y sencillo, con un importante abordaje pedagógico, contiene planteamientos atractivos que ayudarán a todos los lectores a la reflexión, así como interesantes selecciones bibliográficas al final de cada capítulo, para profundizar en los contenidos tratados en cada tema.

En la primera parte, que abarca los cuatro primeros capítulos, se tratan los conceptos básicos de salud, condiciones de trabajo, protección social y el concepto de la propia Salud Laboral.

La segunda parte, que contiene siete capítulos, aborda el marco jurídico y organizacional donde se llevan a cabo los programas preventivos, comenzando por un recorrido histórico de la institucionalización de la Salud Laboral en España.

Una introducción a las técnicas de investigación en Salud Laboral es el contenido de la tercera parte, que incluye las cuantitativas 
y cualitativas de mayor aplicación en este área.

La cuarta parte presenta las bases de la vigilancia de la Salud Laboral, tanto de los riesgos como de los efectos, y en ella se expone el papel de los reconocimientos médicos en este contexto.

Finalmente, la quinta parte, que representa casi la mitad del texto, analiza problemas específicos y los medios para prevenirlos, e incluye, además, un capítulo final que trata de la participación de los trabajadores.

La amplitud y diversidad de los temas tratados ha sido resuelta por los directores a través de la colaboración de 58 expertos con conocimiento y experiencia, como autores de los diferentes temas tratados. Se ha conseguido un balance adecuado entre especialistas de diferentes disciplinas (médicos, químicos, ingenieros, sociólogos, juristas, psicólogos, economistas, etc.), y de diferentes ámbitos profesionales (universidades, administraciones, empresas, etc.), representativos del escenario actual de la seguridad y la salud en el trabajo en nuestro país.

Dada la existencia de pocos libros de texto en castellano que aborden de forma global todos los aspectos, y también todos los enfoques, a tener en cucnta para resolver los problemas que surgen en los centros de trabajo relativos a la prevención de riesgos laborales, los alumnos y profesionales de esta temática recibirán con agrado esta obra, agradeciendo, además, su moderado precio.

En definitiva, este libro constituye una buena herramienta para obtener informaciones y conocimientos sobre la Salud Laboral, siendo de utilidad para los estudiantes de las diversas formaciones de grado y postgrado que en nuestro país se están impartiendo sobre prevención de riesgos en el lugar de trabajo, y para todos los profesionales que trabajan en el campo de la Salud Laboral. 